\title{
CLARIFICATION OF AQUEOUS SUSPENSIONS WITH A HIGH CONTENT OF SUSPENDED SOLIDS IN RAPID SAND FILTERS
}

\author{
Vadym Polyakov \\ Institute of Hydromechanics of the National Academy of Sciences of Ukraine \\ 6/4 Zhelyabova str., Kyiv, Ukraine, 02000 \\ polyakov_igm@list.ru \\ Andriy Kravchuk \\ Department of Water supply and water sewerage \\ Kyiv National University of Construction and Architecture \\ 31 Povitroflotskyi ave., Kyiv, Ukraine, 03680 \\ kravchuk.am@knuba.edu.ua \\ Gennadii Kochetov \\ Department of Water supply and water sewerage \\ Kyiv National University of Construction and Architecture \\ 31 Povitroflotskyi ave., Kyiv, Ukraine, 03680 \\ gkochetov@gmail.com \\ Oleksandr Kravchuk \\ Department of Water supply and water sewerage \\ Kyiv National University of Construction and Architecture \\ 31 Povitroflotskyi ave., Kyiv, Ukraine, 03680 \\ a.a.kravchuk@gmail.com
}

\begin{abstract}
The presented work is devoted to solving the actual problem of increasing the efficiency of rapid sand filters with granular filling, which operate at a constant filtration rate when cleaning suspensions with a relatively high concentration of contaminants. The proposed mathematical model for clarifying the suspension by filtration consists of three interconnected blocks: clarified, filtration, and hydraulic. Convenient dimensionless mathematical dependencies are obtained for calculating the concentrations of contaminants and sediment from the height of the filter and suspension in the filtrate; head loss in the filter loading; the effective time of the filter (the duration of the filter cycle). The design of the experimental setup and the methodology for conducting experimental studies and mathematical processing of the results are valid. The results of experimental studies of the suspension filtering process through the granular loading are presented, and the obtained data is analyzed. Measurement of pressure losses in the filter loading is performed when a suspension is passed with a relatively high concentration of contaminants at various filtration rates. The nature of the change in the filtration rate with time and height (length) loading at various filtration rates and initial contamination concentrations is determined. Measured variable concentration of suspended matter in filtered water and retained contamination over time. As a result of the experiments, it is confirmed that an increase in the concentration of retained contaminants $\mathrm{S}$ leads to an increase in the parameter $\Delta \mathrm{n} / \mathrm{n}$. Upon reaching a certain value of the concentration of the retained sediment $\mathrm{S}$ (in our case $\mathrm{S}=30 \mathrm{~g} / \mathrm{dm}^{3}$ ), an increase in the relative specific volume of the sediment greater than $\Delta \mathrm{n} / \mathrm{n}_{0}=0.65$ is not observed. It is established that an important characteristic of the retained sediment is the ratio of the volume concentration of the sediment to the volume concentration of solid particles in this sediment $\gamma=\mathrm{C}_{\mathrm{sd}} / \mathrm{C}_{\mathrm{s}}$. The values of the adhesion and detachment of particles of contaminant in the particles of the material loading $\bar{\alpha}=4,9 ; \bar{\beta}=0,009$. The results of experimental studies in general confirm the correctness and reliability of the obtained analytical dependencies.
\end{abstract}

Keywords: hydraulic conductivity, filter bed porosity, filtration rate, contaminant concentration, contaminant adhesion factor, contaminant detachment factor. 


\section{Introduction}

Water preparation for the needs of industrial enterprises is carried out according to various technological schemes in order to bring its physico-chemical parameters in line with the requirements of consumers. One of the main components of these schemes is rapid sand filters with granular bed. They play a leading role in the process of water treatment from suspended and colloidal substances. They are intended for partial or almost complete clarification of water depending on the requirements for the treated water and, as a rule, are established at the final stages of treatment [1-3]. The effectiveness of the treatment facilities significantly affects both the quality and cost of the treated water.

The aim of research is conducting experimental studies of the operating parameters of rapid sand filters with granular bed, which are used in industrial wastewater treatment schemes. Implementation of the theoretical analysis of the clarification of aqueous suspensions with a high content of suspended substances using accurate and approximate calculation formulas and equations.

To achieve this goal it is necessary to solve the following tasks:

- to design and manufacture an experimental setup for studying the filtration characteristics of the filter bed;

- to conduct experimental studies of the filtration process of the studied process water and to determine the optimal modes of operation of treatment plants.

The objective of these studies is attempt to systematize the experimental data and proposition of the most advanced mathematical model, which describes the process of removing contaminants by granular bed of rapid sand filters.

A large number of papers have been devoted to the study of rapid sand filters, for example [4-8].

Historically, the first fundamental work on this issue can be identified theoretical and experimental studies [5]. Based on the analysis of a large amount of experimental material for describing the process of removing contaminants by granular filter bed, a system of differential equations is proposed.

- Substance balance equation:

$$
\frac{\partial \mathrm{S}}{\partial \mathrm{t}}=-\mathrm{V} \frac{\partial \mathrm{C}}{\partial \mathrm{x}}
$$

where $\mathrm{S}$ - the mass of sediment accumulated at a given time in a unit bed volume, $\mathrm{g} / \mathrm{m}^{3} ; \mathrm{t}$ - duration of the filtration process, $\mathrm{h} ; \mathrm{V}$ - filtration rate, $\mathrm{m} / \mathrm{h} ; \mathrm{C}$ - mass concentration of suspended substance in water, $\mathrm{g} / \mathrm{m}^{3} ; \mathrm{x}$ - vertical coordinate, $\mathrm{m}$

- Equation of linear kinetics of mass transfer:

$$
-\frac{\partial C}{\partial x}=\tilde{\alpha} C-\frac{\beta}{V} S
$$

where $\tilde{\alpha}$ - reduced rate of adhesion of suspended particles to the surface of the filter bed grains, $\mathrm{m}^{-1} ; \beta$ - coefficient of detachment rate of previously adhering suspended particles, $\mathrm{s}^{-1}[9,10]$. These rates depend on the rate of filtration, the physico-chemical properties of the filtration material, and the particles of impurities contained in the source water.

The effect of water clarification with each elementary layer of filter bed should be considered as the total result of two opposite processes: the process of extracting particles from water and their attachment to the bed grains and the process of detaching previously adhered particles and returning them to water.

Numerical methods are used, for example, in [11-13]. Analytical methods for solving a system of initial equations describing the features of the operation of rapid sand filters are considered in $[14,15]$. On the basis of the obtained solutions, the author proposes quite reasonable and easy-to-use calculated dependencies for determining the main technological characteristics of the structures under consideration. 


\section{Materials and methods for the study of parameters of rapid sand filters}

\section{1. Experimental device}

To carry out experimental studies of the operating parameters of rapid sand filters, a laboratory experimental setup has been designed and installed, the scheme of which is shown in Fig. 1.

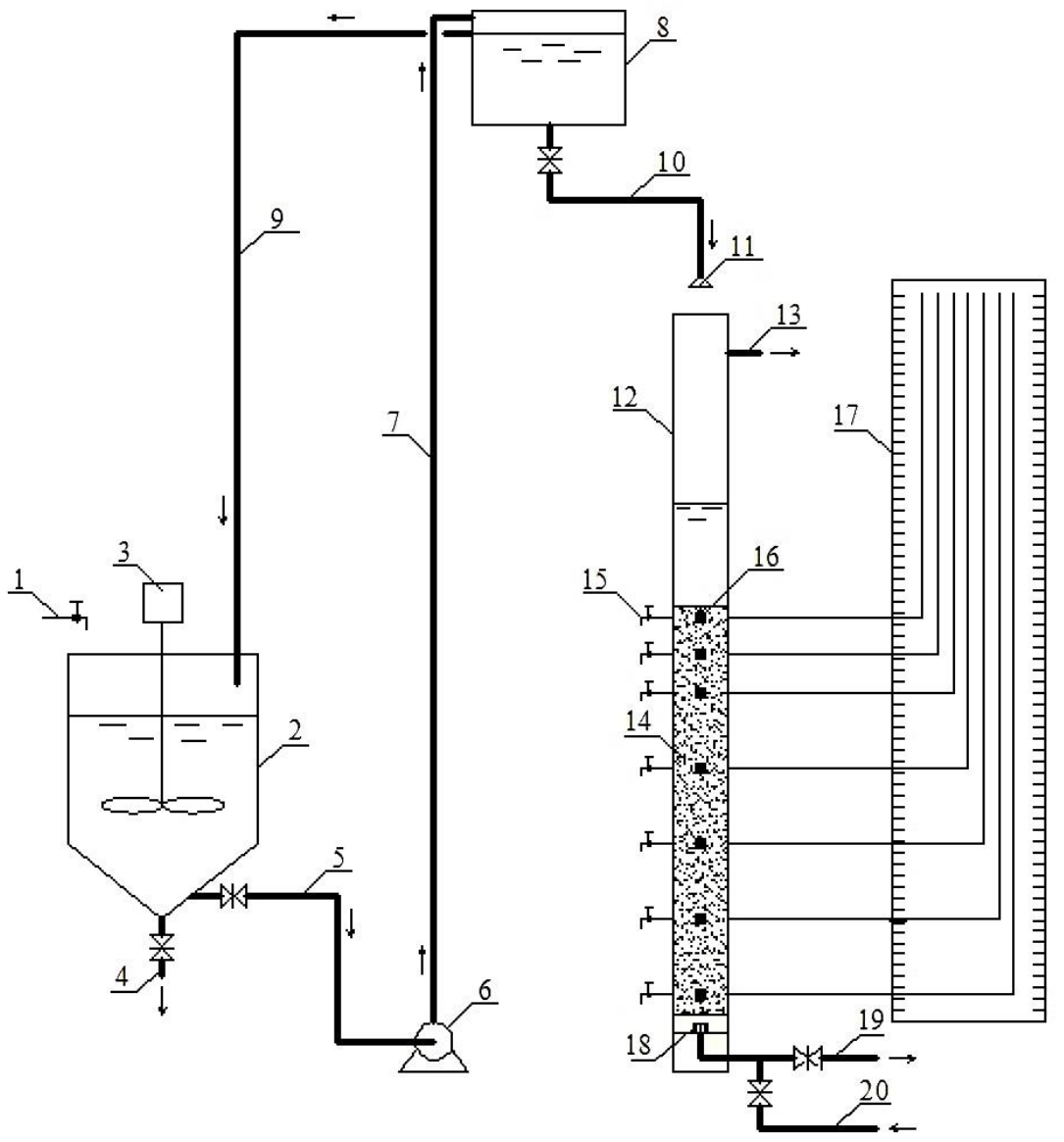

Fig. 1. Scheme of the experimental setup: 1 - water supply from the water supply network; 2 - suspension tank; 3 - mechanical stirrer; 4 -discharge into the sewer; 5 -pipeline for supplying suspension to the pump; 6 - pump; 7 - pressure pipeline of supply suspension to the feed tank; 8 - feed tank; 9 - overflow pipeline; 10 - pipeline for supplying the suspension to the filter; 11 - distribution device; 12 - filter column; 13 - overflow pipeline; 14 - filter bed;

15 -suspension sampling valves; 16 - place for bed sampling; 17 - piezometers shield; 18 - drainage cap 19 - pipeline for removal of clarified water; 20 - water supply pipeline for backwashing

\section{2. Methods of conducting experimental studies}

The filtration column was made of PVC pipe $\varnothing 150 \mathrm{~mm}, 2 \mathrm{~m}$ high. The top remained open, the bottom was sealed. The height of the sand bed (14) was $1.0 \mathrm{~m}$. On the pipe equipped 7 holes $(1,2,3$ - at a distance of $0.1 \mathrm{~m}, 4,5,6,7$ - through $0.2 \mathrm{~m})$, in which water extraction, cleaned (15), and sand samples (16) after the filtration process. In the same sections, special piezometric tubes (17) were connected to obtain pressure readings in the corresponding sections of the filtration bed. Also volumetric method was measured water flow.

When conducting experimental studies, the filtration rate varied within $\mathrm{V}=3 \div 12 \mathrm{~m} / \mathrm{h}$; A spondyl clay was used as contamination, the initial mass concentration of contamination was $\mathrm{C}_{0}=100 \div 200 \mathrm{mg} / \mathrm{dm}^{3}$.

Samples of filtered water and sand were taken every hour. At the same time, the dynamics of changes in their indicators over time was recorded. The volume of water and sand samples taken 
during the experiment was less, respectively, $5 \%$ and $1 \%$ of the volume of the suspension and filter media. This circumstance, in accordance with the recommendations of [16], did not significantly affect the parameters of the model flow.

The completion of the experimental filter setup in a particular experiment, and therefore the duration of the filter cycle occurred when a certain specific concentration of contaminants was reached at the outlet of the filter column.

\section{3. Characterization of the filtration material and impurities}

\section{3. 1. Sand bulk density}

The bulk density of the sand in the standard unconsolidated state was determined by weighing the sample of material dried to constant weight and calculated by the formula:

$$
\rho_{\mathrm{b}}=\frac{\mathrm{m}_{1}-\mathrm{m}}{\mathrm{V}}=\frac{1612-200}{1000}=1,412, \mathrm{~g} / \mathrm{cm}^{3},
$$

where $\mathrm{m}$ - the mass of the measuring vessel; $\mathrm{m}_{1}$ - the mass of the measuring vessel with sand; $\mathrm{V}$ the volume of the measuring vessel, $\mathrm{cm}^{3}$.

\section{3. 2. True sand density}

The true density of solid materials was determined using the Le Chatelier device and calculated by the formula:

$$
\rho_{\mathrm{i}}=\frac{\mathrm{m}_{1}-\mathrm{m}_{2}}{\mathrm{~V}}=\frac{443-390}{200}=2,65, \mathrm{~g} / \mathrm{cm}^{3}
$$

where $\mathrm{m}_{1}$ - the mass of the flask after the sand pouring, $\mathrm{g} ; \mathrm{m}_{2}-$ the mass of the flask before the sample pouring, $\mathrm{g} ; \mathrm{V}$ - the volume of sand is equal to the volume of the eject fluid, $\mathrm{cm}^{3}$.

\section{3. 3. Porosity of filter bed}

Porosity was calculated by the formula:

$$
\mathrm{H}=\mathrm{n}=\left(1-\frac{\rho_{\mathrm{n}}}{\rho_{\mathrm{i}}}\right) \cdot 100 \%=\left(1-\frac{1412}{2650}\right) \cdot 100 \%=47 \%
$$

\section{3. 4. Equivalent diameter of sand particles}

In determining the equivalent diameter of sand particles, the Le Chatelier device was also used. The equivalent particle diameter was $\mathrm{D}_{\mathrm{eq}}=0.0015 \mathrm{~m}$. The average value of the sand particle shape factor was $\mathrm{k}_{\mathrm{f}}=1.19$.

\section{3. 5. The average particle diameter of spondyl clay}

For this, the test clay was ground to a powder. Determination of the average particle size was carried out using the instrument PSC-2. According to the results of the measurements, it was found that the average diameter of clay particles is $\mathrm{d}_{\mathrm{av}}=0.0000077 \mathrm{~m}=7.7 \mu \mathrm{m}$.

\section{The results of experimental and theoretical studies of rapid sand filters}

\section{1. Head loss}

Before conducting basic research on an assembled experimental model, a separate series of measurements of the hydraulic and filtration characteristics of the filtration material of the unpowered filter bed with the passage of pure water is previously performed. The filtration rate of the clean sand was $\mathrm{k}_{0}=49 \mathrm{~m} / \mathrm{h}$.

The next series of experimental studies is devoted to determining the change in head loss in the filter over time with the passage of various water flow rates (filtration rates) and different initial concentrations of contaminants. Some typical measurement results are shown in Fig. 2. 


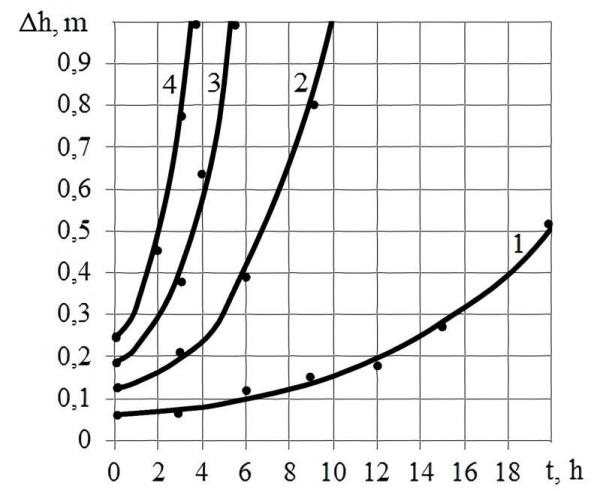

Fig. 2. Change of head loss in the filter at $\mathrm{C}_{0}=200 \mathrm{mg} / \mathrm{l}$ and filtration rate:

$1-\mathrm{V}=3.0 \mathrm{~m} / \mathrm{h} ; 2-\mathrm{V}=6.0 \mathrm{~m} / \mathrm{h} ; 3-\mathrm{V}=9.0 \mathrm{~m} / \mathrm{h} ; 4-\mathrm{V}=12.0 \mathrm{~m} / \mathrm{h}$

From the graphs in Fig. 2 it follows that increasing the filtration rate leads to a significant increase in head loss. Their increase with time is also obvious. In addition, it is found that during the entire filtration time, the main head losses occur in the initial layers of the filter bed. In the following, through the thickness of the bed sections, the head loss decreases sharply. Fig. 3 shows at what height (depth) of the filter some kind of head loss arises.

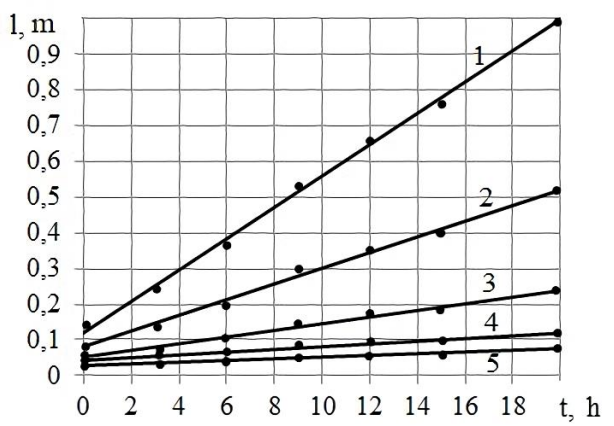

Fig. 3. Determination of head loss at different heights of the filter: $1-100 \% \Delta \mathrm{h} ; 2-90 \% \Delta \mathrm{h} ; 3-80 \% \Delta \mathrm{h} ; 4-70 \% \Delta \mathrm{h} ; 5-50 \% \Delta \mathrm{h}$

From Fig. 3 it follows that $100 \%$ of head loss is achieved at the entire depth (height) of the filter ( $\mathrm{L}=1 \mathrm{~m}), 80 \%$ of head loss will be at a depth of $\mathrm{l}=0.25 \mathrm{~m}, 50 \%$ - at a depth of $\mathrm{l}=0.07 \mathrm{~m}$.

An important generalized parameter that comprehensively takes into account the characteristics of the hydraulic and filtration characteristics of the filter bed can be the hydraulic conductivity $\mathrm{k}$. It is obvious that the retention of a granular bed of particles of contaminant leads to a change in its properties and characteristics, including pressure loss and filtration rate.

When conducting these studies, the nature of the change in the hydraulic conductivity with time in bed height (length) was determined at different filtration rates. As an example, Fig. 4 shows the results of experiments to determine the relative the hydraulic conductivity $\left(\overline{\mathrm{k}}=\mathrm{k} / \mathrm{k}_{0}\right)$ with height for the case of the initial concentration of contaminants $\mathrm{C}_{0}=200 \mathrm{mg} / \mathrm{l}$ and the filtration rate $\mathrm{V}=6.0 \mathrm{~m} / \mathrm{h}$. Here, the dotted line shows the character of the change of hydraulic conductivity with the time for the whole filter.

From the graph in Fig. 4 it follows that the most intensive decrease in the hydraulic conductivity in the bed height occurs in the first section following the movement of the fluid. The further the target is located from the initial one, the weaker is the intensity of the decrease in the hydraulic conductivity. In all cross sections, the most intensive decrease in the corresponding relative hydraulic conductivity also takes place in the initial periods of the filter operation. Over time, this intensity decreases and in the last lower layer of the bed has the lowest value. 


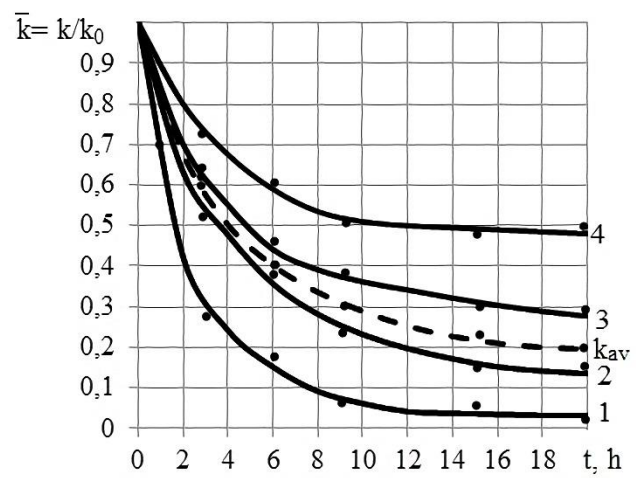

Fig. 4. The change in the relative hydraulic conductivity of different bed layers over a period of time: 1 - between holes $1-2 ; 2$ - between holes $2-3$; 3 - between holes $3-4 ; 4$ - between holes $6-7$

\section{2. Clarifying effect at different filtration rates and filter operation time}

The next important step in conducting the presented studies is measuring the nature of the change in the concentration of contaminants over time in different sections along the height of the filter, as well as at its end. In this case, the experiments are carried out at different filtration rates. Separate, characteristic results of experiments with an initial concentration of contaminant $\mathrm{C}_{0}=200 \mathrm{mg} / \mathrm{l}$ are shown in Fig. 5.

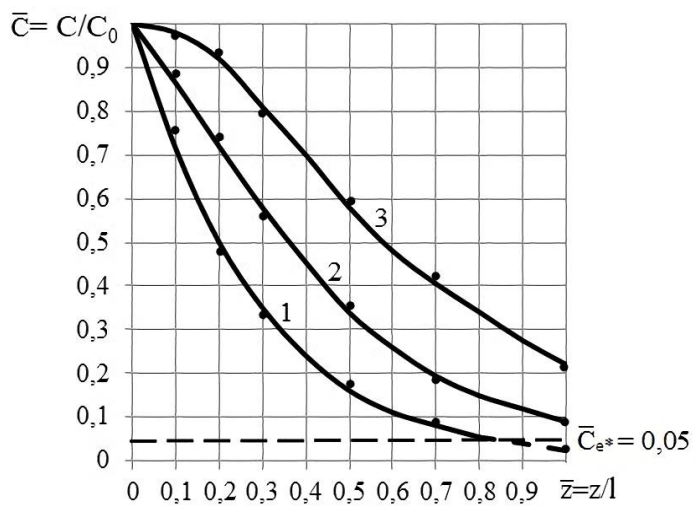

Fig. 5. The change in the relative concentration of contaminant $\left(\bar{C}=C / C_{0}\right)$ along the height of the filter $(\overline{\mathrm{Z}}=\mathrm{z} / \mathrm{L})$ at a filtration rate of $\mathrm{V}=6.0 \mathrm{~m} / \mathrm{h}$ during operation: $1-\mathrm{t}=3 \mathrm{~h} ; 2-\mathrm{t}=15 \mathrm{~h} ; 3-\mathrm{t}=30 \mathrm{~h}$

The data in Fig. 5 show that the maximum degree of clarification takes place at a bed depth of up to $0.3 \mathrm{~m}$. For a certain time, the degree of clarification at the initial sections of the filter decreases and the layers in the bed depth begin to work more intensively. In addition, it should be noted that an increase in the filtration rate with all other equal characteristics leads to a decrease in the degree of removal of contaminants along the height of the filter. And, at the same time, to a more rapid clogging of this bed by contamination, which leads to a decrease in the effective operation of the structure, that is, a decrease in the filter cycle time.

In the presented graphs, the dashed horizontal line is limited by the minimum relative concentration of contamination $\left(\overline{\mathrm{C}}_{\mathrm{e} *}=0,05\right)$, which must be ensured when cleaning this unit. According to the graphs, at a filtration rate of $\mathrm{V}=6.0 \mathrm{~m} / \mathrm{h}$, the filter will provide the necessary degree of treatment of $95 \%$ during 9 hours.

A graph illustrating the dependence of the change in the intensity of the removal of contaminants during a certain operating time and depth of filter bed is shown in Fig. 6.

Graphical dependencies shown in Fig. $\mathbf{6}$ also indicate that the greatest intensity of the removal of contaminants from a liquid takes place in the upper layers of the filter during the initial filtration periods. Over time, the removal rate in the upper layers comes, and in the lower layers it grows. 


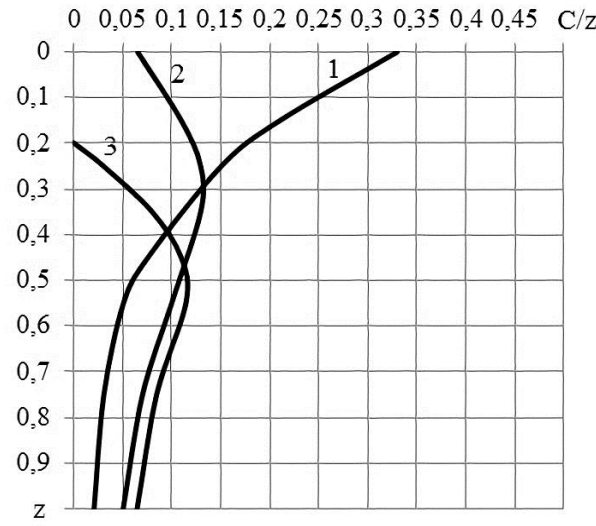

Fig. 6. The change in the intensity of the removal of contaminants $(\mathrm{C} / \mathrm{z})$ with time at a filtration rate of $\mathrm{V}=6.0 \mathrm{~m} / \mathrm{h} ; 1-\mathrm{t}=3 \mathrm{~h} ; 2-\mathrm{t}=15 \mathrm{~h} ; 3-\mathrm{t}=30 \mathrm{~h}$

Useful for evaluating the effectiveness of the process of water clarification on the filter are also obtained by us and are shown in Fig. 7 graphs showing the change in the relative concentration of contaminants in the final section of the treatment structure $\left(\overline{\mathrm{C}}_{\mathrm{e}}=\mathrm{C}_{\mathrm{e}} / \mathrm{C}_{0}\right)$ over time during the cleaning of the suspension with the initial concentration of the suspension $C_{0}=200 \mathrm{mg} / \mathrm{l}$ depending on the filtration rate $\mathrm{V}$. This graph also shows the dotted line the limit of permissible clarification $(95 \%)$ on the filter structure.

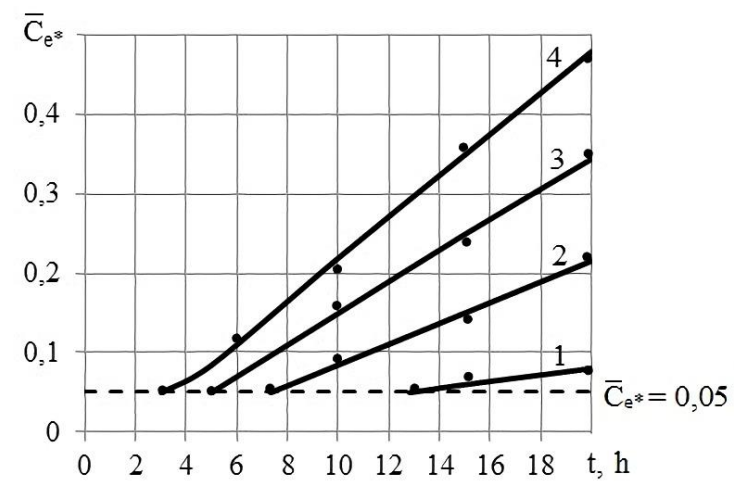

Fig. 7. The change in the relative concentration of impurities in the final section of the filter with time at the filtration rate: $1-\mathrm{V}=3.0 \mathrm{~m} / \mathrm{h} ; 2-\mathrm{V}=6.0 \mathrm{~m} / \mathrm{h} ; 3-\mathrm{V}=9.0 \mathrm{~m} / \mathrm{h} ; 4-\mathrm{V}=12.0 \mathrm{~m} / \mathrm{h}$

In the process of conducting experiments, a series of studies is carried out to determine the concentration of contaminants retained by filter bed. As an example, Fig. 8 shows the results of measurements of the concentration of retained contaminants $(\mathrm{S})$ at the bed height for the case of filtration a suspension with an initial concentration of contaminants $\mathrm{C}_{0}=200 \mathrm{mg} / \mathrm{l}$ at a filtration rate of $\mathrm{V}=6.0 \mathrm{~m} / \mathrm{h}$. It also implies that the sediment is retained in the upper layers of the filter during the entire time of its operation. The distribution of the mass of contaminants according to the height of the bed layer depends on the type of granular filter bed, the type of contaminants that are removed during clarification, the operation time of the structure and filtration conditions.

In this case, with a total bed thickness of $1 \mathrm{~m}$ in the first layer $0.2 \mathrm{~m}$ thick, more than $50 \%$ of the total mass of contaminants is retained. Fig. 9 shows the mass distribution of retained contaminants after 20 hours of operation of the filter. According to this graph, it follows that the bulk of the contaminant (up to $95 \%$ ) is retai ned between holes No. 1-4, at a filter bed thickness of 0.4 $\mathrm{m}$. Similar results are obtained by the authors in [17].

The change in the intensity of accumulation of retained contaminants by the depth of the filter bed with time is shown in Fig. 10. The nature of its change is fully consistent with the intensity of removing contaminants from a liquid (Fig. 6). It reaches the highest values in the initial bed layers in the direction of fluid flow. 


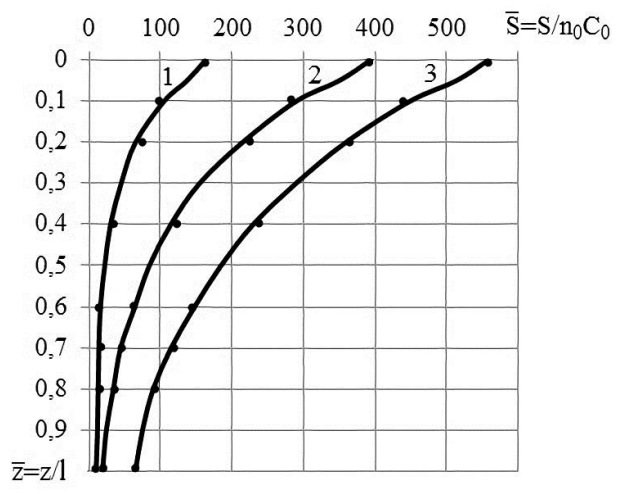

Fig. 8. The change in the relative concentration of retained contaminants $\bar{S}=S / n_{0} C_{0}$ over the filter thickness over time: $1-\mathrm{t}=3 \mathrm{~h} ; 2-\mathrm{t}=15 \mathrm{~h} ; 3-\mathrm{t}=30 \mathrm{~h}$

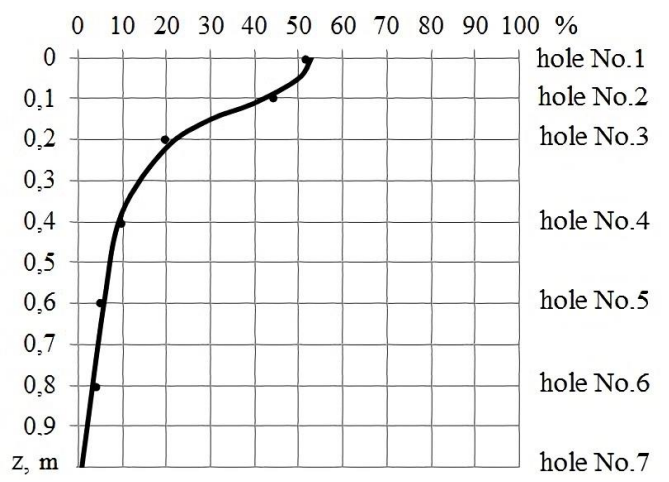

Fig. 9. Mass distribution of contaminants at the filter height after 20 hours of its operation

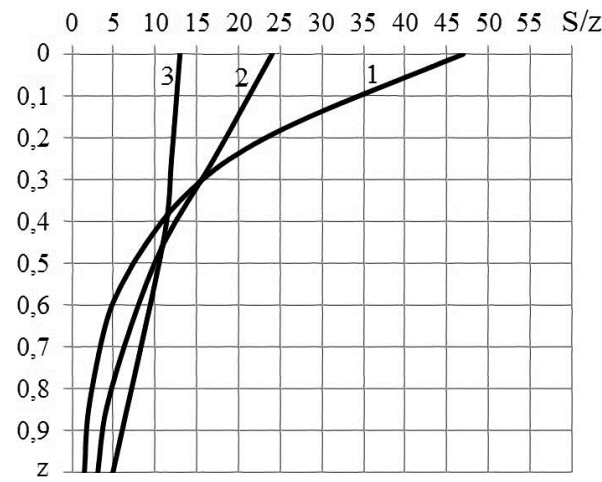

Fig. 10. The change in the intensity of accumulation of contaminant by the filter bed depth and in time: $1-\mathrm{t}=3 \mathrm{~h} ; 2-\mathrm{t}=15 \mathrm{~h} ; 3-\mathrm{t}=30 \mathrm{~h}$

\section{3. Change in filter bed characteristics}

In the process of filtration, particles of contamination are retained and they accumulate in the pores between the particles of the medium. This leads to a decrease in the volume of pores, that is, to a decrease in the porosity of the filter material. It is possible to write

$$
\Delta \mathrm{n}=\mathrm{n}_{0}-\mathrm{n},
$$

where $\Delta \mathrm{n}$ - the change (decrease) in the porosity of the filter material during the filter operation time; $\mathrm{n}_{0}$ - the initial porosity of the clean filter bed; $\mathrm{n}$ - a variable with time porosity of clogged bed material.

The value of $\Delta \mathrm{n}$ can be interpreted as the volume of sediment accumulated (retained) in a bed volume unit (specific volume of sediment). The ratio $\Delta \overline{\mathrm{n}}=\Delta \mathrm{n} / \mathrm{n}_{0}$ is called the relative specific volume of sediment or the relative saturation of the pore space. 
The results of our studies have shown that an increase in the relative specific volume of sediment $\Delta \overline{\mathrm{n}}$ (a decrease in the free pore bed space $\Delta \mathrm{n}$ ) due to the influence of trapped particles of contaminant causes a significant decrease in the relative filtration rate of the granular bed. This dependence is adequately described by the dependence obtained in experiments [4]

$$
\Delta \overline{\mathrm{n}}=1-\sqrt[3]{\overline{\mathrm{k}}}
$$

It is obvious that the value of the specific volume of sediment $\Delta \mathrm{n}$ and the relative specific volume of sediment $\Delta \overline{\mathrm{n}}$ depend on the value of the relative concentration of contaminants $(\overline{\mathrm{S}})$, retained by bed the filter. Dependence on can be represented as

$$
\Delta \overline{\mathrm{n}}=0,7 \operatorname{th}\left(0,00124 \mathrm{n}_{0} \mathrm{C}_{0} \overline{\mathrm{S}}\right)
$$

The analysis of the experimental data also shows that an increase in the concentration of a sediment retained by filter bed leads to a corresponding decrease in the value of its relative filtration rate.

In the analysis and mathematical description of filtration processes that take place during water treatment, an important characteristic of the retained sediment is the ratio of the volume concentration of sediment to the volume concentration of solid particles in this sediment.

$$
\gamma=\frac{\mathrm{S}_{\mathrm{S}}}{\mathrm{S}_{\mathrm{s} . \mathrm{p}}}
$$

This indicator can be expressed in terms of the mass concentration of the retained sediment and the solid phase in it (density ratio). On the basis of the carried out experimental studies, an empirical dependence has been obtained for determining the index $\gamma$ in the form

$$
\gamma=-67 \Delta \overline{\mathrm{n}}+57
$$

The accumulation of sediment in the pore space is accompanied by its compaction, and this in turn causes an increase in the concentration of the solid phase in it and, accordingly, an increase in the density of this retained sediment.

\section{4. Value of adhesion (a) and detachment $(\boldsymbol{\beta})$ rates}

To determine the rate of adhesion of contaminant particles in the filter bed (a), let's use the original equation (2), which describes the kinetics of contaminant removal during filtration in the form of

$$
-\mathrm{V} \frac{\partial \mathrm{C}}{\partial \mathrm{z}}=\alpha \mathrm{C}-\beta \mathrm{S}
$$

In the initial period of the filter operation, only the removal and accumulation of contaminant occurs, and the detachment of particles of contaminant is practically absent. That is, for this time, the second term in the right side of equation (11) can be neglected. Then it will look

$$
\mathrm{V} \frac{\partial \mathrm{C}}{\partial \mathrm{z}}=-\alpha \mathrm{C}
$$

Solution (12) under the boundary conditions: $\mathrm{z}=0 ; \mathrm{C}=\mathrm{C}_{0}$ gives

$$
\ln \frac{C}{C_{0}}=-\frac{\alpha}{V} z
$$


where $\mathrm{C}_{0}$ - the volume concentration of contaminants the initial section of the filter; $\mathrm{C}$ - variable volume concentration of contaminants in the cross section at the height of the filter $\mathrm{z}$.

From the last dependency let's find:

$$
\alpha=-\frac{\mathrm{V}}{\mathrm{z}} \ln \frac{\mathrm{C}}{\mathrm{C}_{0}} .
$$

To determine the detachment velocity rate $\beta$, let's use the ratio

$$
\frac{\mathrm{S}_{02}}{\mathrm{~S}_{01}}=\frac{1-\mathrm{e}^{-\beta \mathrm{t}_{2}}}{1-\mathrm{e}^{-\beta \mathrm{t}_{1}}},
$$

where $\mathrm{S}_{01}, \mathrm{~S}_{02}$ - the concentrations of contaminants retained in the initial cross section of the filter, during the operation, respectively, $t_{1}$ and $t_{2}$.

To find the specific values of the coefficients a and $\beta$, let's use the experimental data to determine the variable values of the relative concentration of contaminants in the filtered liquid $\overline{\mathrm{C}}=\mathrm{C} / \mathrm{C}_{0}$ and the relative concentration of contaminants retained by filter bed $\overline{\mathrm{S}}=\mathrm{S} / \mathrm{n}_{0} \mathrm{C}_{0}$, according to Fig. 5, 8. These calculations are presented in Fig. 11, 12.

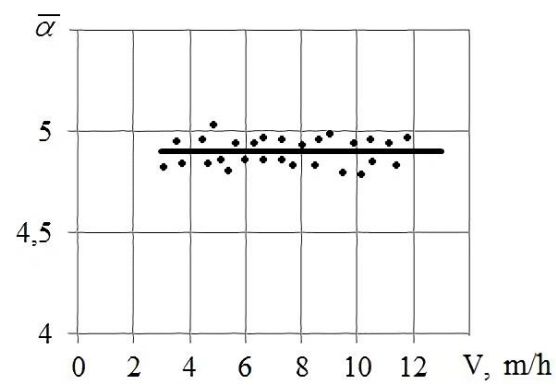

Fig. 11. Determination of the relative coefficient $\bar{\alpha}=\alpha \mathrm{L} / \mathrm{V}_{0}$

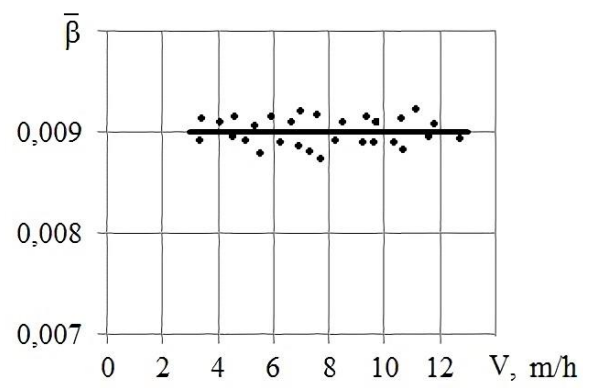

Fig. 12. Determination of the relative coefficient $\bar{\beta}=\beta \mathrm{n}_{0} \mathrm{~L} / \mathrm{V}_{0}$

Finally, let's obtain: the value of the relative adhesion coefficient $\bar{\alpha}=4,9$; value of the relative detachment coefficient $\bar{\beta}=0,009$.

\section{5. Theoretical substantiation of the filtration process}

The prediction of water clarification filters, the justification of its technological parameters can be reliably performed only using the methods of mathematical modeling. As shown by the results of our fundamental experimental studies of clarification and filtration processes on rapid sand filters, when filtration with a constant rate $\mathrm{V}$, the change in the physicochemical environment in a homogeneous layer of well-fitration material (conditioned sand) is almost adequately described by a mathematical model that consists of two related blocks (clarification and filtration) and reflects both sides of the interphase mass transfer-adhesion of particles under the action of hydrodynamic force. The clarification block in this case includes linear equations of mass transfer and mass exchange [5, 18] 


$$
\begin{aligned}
& \mathrm{V} \frac{\partial \mathrm{C}}{\partial \mathrm{z}}+\frac{\partial \mathrm{S}}{\partial \mathrm{t}}=0 \\
& \frac{\partial \mathrm{S}}{\partial \mathrm{t}}=\alpha \mathrm{C}-\beta \mathrm{S} .
\end{aligned}
$$

System (16), (17) is supplemented by boundary and initial conditions.

$$
\mathrm{z}=0, \mathrm{C}=\mathrm{C}_{0} ; \mathrm{t}=0, \mathrm{~S}=0 \text {. }
$$

Here $\mathrm{C}, \mathrm{S}$ - the volumetric concentrations of suspended and sedimented particles of the suspension; $\alpha, \beta$ - constant rates of adhesion of suspended and detachment of sedimented particles when $\mathrm{V}=$ const; the initial concentration of impurities in the suspension is considered constant, and the filter bed is clean at the beginning.

During the experiments, the validity of the generalized Darcy law is established, and then the filtration unit includes a system of equations [19]

$$
\begin{gathered}
\mathrm{V}=-\mathrm{k}\left(\mathrm{S}_{\mathrm{S}}\right) \frac{\partial \mathrm{h}}{\partial \mathrm{z}}, \\
\mathrm{k}\left(\mathrm{S}_{\mathrm{S}}\right)=\mathrm{k}_{0} \cdot \mathrm{f}\left(\mathrm{S}_{\mathrm{S}}\right), \\
\mathrm{S}_{\mathrm{S}}=\gamma(\mathrm{S}) \mathrm{S},
\end{gathered}
$$

and boundary condition

$$
\mathrm{z}=\mathrm{L}, \mathrm{h}=\mathrm{H}_{\mathrm{d}} \text {. }
$$

Here $\mathrm{k}, \mathrm{k}_{0}$ - the current and initial filtration rates; $\mathrm{S}_{\mathrm{S}}$ - volume concentration of sediment; $\mathrm{h}$ - piezometric head; $\gamma(\mathrm{S})$ - the state function of the sediment, which characterizes the fractional contribution of suspension particles (formulas (9), (10)) [20], $\mathrm{S}_{\mathrm{S}}$ is associated with $\Delta \mathrm{n}$ as follows: $\Delta \mathrm{n}=\mathrm{n}_{0}-\mathrm{S}_{\mathrm{S}} ; \mathrm{L}-$ the height of the filter bed; $\mathrm{H}_{\mathrm{d}}-$ constant pressure at the exit from it. According to the experimental studies (formula (7)) for the function $f\left(S_{S}\right)$ with regard to (22), the following

$$
f\left(S_{S}\right)=\left(1-\frac{S_{S}}{n_{0}}\right)^{3}=\left[1-\frac{\gamma(S) \cdot S}{n_{0}}\right]^{3} .
$$

To summarize the theoretical analysis, dimensionless variables and parameters are introduced:

$$
\begin{gathered}
\overline{\mathrm{C}}=\frac{\mathrm{C}}{\mathrm{C}_{0}}, \\
\overline{\mathrm{S}}=\frac{\mathrm{S}}{\mathrm{n}_{0} \mathrm{C}_{0}}, \\
\overline{\mathrm{z}}=\frac{\mathrm{z}}{\mathrm{L}}, \\
\overline{\mathrm{t}}=\frac{\mathrm{Vt}}{\mathrm{n}_{0} \mathrm{~L}}, \\
\overline{\mathrm{h}}=\mathrm{k}_{0} \frac{\mathrm{h}-\mathrm{H}_{\mathrm{d}}}{\mathrm{VL}},
\end{gathered}
$$




$$
\begin{gathered}
\bar{\alpha}=\frac{\alpha \mathrm{L}}{\mathrm{V}}, \\
\bar{\beta}=\frac{\mathrm{n}_{0} \mathrm{~L} \beta}{\mathrm{V}}, \\
\overline{\mathrm{k}}=\frac{\mathrm{k}}{\mathrm{k}_{0}} .
\end{gathered}
$$

Then the mathematical model is simplified to the following form.

$$
\begin{gathered}
\mathrm{V}=-\mathrm{k}\left(\mathrm{S}_{\mathrm{S}}\right) \frac{\partial \mathrm{h}}{\partial \mathrm{z}} ; \\
\mathrm{k}\left(\mathrm{S}_{\mathrm{S}}\right)=\mathrm{k}_{0} \cdot \mathrm{f}\left(\mathrm{S}_{\mathrm{S}}\right) ; \\
\overline{\mathrm{z}}=0, \overline{\mathrm{C}}=1 ; \overline{\mathrm{t}}=0, \overline{\mathrm{S}}=0 ; \\
\overline{\mathrm{k}}(\overline{\mathrm{S}}) \frac{\partial \overline{\mathrm{h}}}{\partial \overline{\mathrm{z}}}=-1 ; \\
\overline{\mathrm{k}}(\overline{\mathrm{S}})=\mathrm{f}(\overline{\mathrm{S}} \cdot \bar{\gamma}(\overline{\mathrm{S}})) ; \\
\overline{\mathrm{z}}=1, \overline{\mathrm{h}}=0 .
\end{gathered}
$$

The function $f(\bar{S})$ is specified taking into account (10) and the expression for $\bar{S}_{S}$

$$
\overline{\mathrm{S}}_{\mathrm{S}}(\overline{\mathrm{S}})=\frac{57 \overline{\mathrm{S}}}{1+67 \mathrm{C}_{0} \overline{\mathrm{S}}}
$$

So

$$
f(\bar{S})=\left(\frac{1+10 C_{0} \bar{S}}{1+67 C_{0} \bar{S}}\right)^{3}
$$

Further, only the filtration mode with $\mathrm{V}=$ const is considered using analytical methods. Then the strict solution of problem (24)-(29) is known and is expressed by dependencies [21]

$$
\begin{gathered}
\overline{\mathrm{C}}(\overline{\mathrm{z}}, \overline{\mathrm{t}})=\mathrm{e}^{-\overline{\alpha \bar{z}}}\left[\mathrm{e}^{-\bar{\beta} \overline{\mathrm{\beta}}} \mathrm{I}_{0}(2 \sqrt{\bar{\alpha} \bar{\beta} \overline{\overline{\mathrm{z}}}})+\beta \int_{0}^{\overline{\mathrm{t}}} \mathrm{e}^{-\bar{\beta} \zeta} \mathrm{I}_{0}(2 \sqrt{\bar{\alpha} \bar{\beta} \overline{\bar{z}} \zeta}) \mathrm{d} \zeta\right] \\
\overline{\mathrm{S}}(\overline{\mathrm{z}}, \overline{\mathrm{t}})=\overline{\alpha \mathrm{e}^{-\overline{\alpha \bar{z}}}} \int_{0}^{\overline{\mathrm{t}}} \mathrm{e}^{-\bar{\beta} \zeta} \mathrm{I}_{0}(2 \sqrt{\bar{\alpha} \bar{\beta} \overline{\mathrm{z}} \zeta}) \mathrm{d} \zeta, \\
\Delta \overline{\mathrm{h}}(\overline{\mathrm{t}})=\int_{0}^{1} \frac{\mathrm{d} \overline{\mathrm{z}}}{\mathrm{f}(\overline{\mathrm{S}}(\overline{\mathrm{z}}, \overline{\mathrm{t}}))},
\end{gathered}
$$

where $\mathrm{I}_{0}$ - means the Bessel function of an imaginary argument of the first kind of zero order, $\Delta \overline{\mathrm{h}}-$ the relative head loss in the filter bed.

Dependencies (32)-(34) serve as the basis for the theoretical substantiation of the effective filter operation time (the duration of the filter cycle) $t_{\mathrm{f}}$. It is a strict requirement regarding the quality of the filtrate, namely, the condition

$$
\overline{\mathrm{C}}_{\mathrm{e}}(\overline{\mathrm{t}})=\overline{\mathrm{C}}(1, \overline{\mathrm{t}}) \leq \overline{\mathrm{C}}_{*}
$$


where $\mathrm{C}_{*}, \mathrm{C}_{\mathrm{e}}$ - the maximum permissible and initial concentration of suspended substance in water. The time of the protective action of the filter bed $t_{p}$, during which the content of contaminants at the exit of the bed does not exceed the standard value, should be found by selecting from the equation

$$
\overline{\mathrm{C}}_{\mathrm{e}}\left(\overline{\mathrm{t}}_{\mathrm{p}}\right)=\overline{\mathrm{C}}_{*} \text {. }
$$

At the same time, when $V=$ const, it is necessary to calculate the growth time $t_{h}$ of the head loss in the filter bed up to the maximum permissible value $\Delta \mathrm{h}_{*}$, that is,

$$
\Delta \overline{\mathrm{h}}\left(\overline{\mathrm{t}}_{\mathrm{h}}\right)=\Delta \overline{\mathrm{h}}_{*} .
$$

It is advisable to identify the main technological time $\bar{t}_{f}$ with the smallest one with $\bar{t}_{p}$, $\bar{t}_{h}$, so that

$$
\bar{t}_{\mathrm{f}}=\min \left(\bar{t}_{\mathrm{p}}, \bar{t}_{\mathrm{h}}\right)
$$

A successful alternative to the accurate solution (32)-(34) is a highly accurate approximate solution [22], which, due to its simplicity, is convenient for a variety of analysis: predictive calculations, substantiation of design and technological parameters, and verification based on experimental data of model rates. So, for engineering calculations, the following approximate dependencies are recommended.

$$
\begin{aligned}
& \bar{C}_{\mathrm{e}}(\overline{\mathrm{t}})=2 \mathrm{e}^{-\frac{2 \bar{\alpha}}{2+\bar{\beta} \overline{\mathrm{t}}}}-\mathrm{e}^{-\bar{\alpha}}, \\
& \overline{\mathrm{S}}(\overline{\mathrm{z}}, \overline{\mathrm{t}})=\frac{2 \bar{\alpha} \overline{\mathrm{t}}}{2+\bar{\beta} \overline{\mathrm{t}}} \mathrm{e}^{-\frac{2 \overline{\alpha \bar{z}}}{2+\bar{\beta} \overline{\mathrm{t}}}},
\end{aligned}
$$

and taking into account the obtained experimental data

$$
\Delta \overline{\mathrm{h}}(\overline{\mathrm{t}})=\int_{0}^{1}\left[\frac{1+67 \mathrm{C}_{0} \overline{\mathrm{S}}(\overline{\mathrm{z}}, \overline{\mathrm{t}})}{1+10 \mathrm{C}_{0} \overline{\mathrm{S}}(\overline{\mathrm{z}}, \overline{\mathrm{t}})}\right]^{3} d \overline{\mathrm{t}} .
$$

It should be noted that formula (40) is valid at $f(\bar{S})$ with (31) for both solutions presented above, but in the case of an approximate solution for $\Delta \overline{\mathrm{h}}$ it is in principle not difficult to derive a cumbersome analytical expression that will contain only elementary functions. If for $\gamma$ to take the average value, then the corresponding formula for $\Delta \overline{\mathrm{h}}(\overline{\mathrm{t}})$ is given in [22].

In order to test the results of experimental and theoretical studies, assess the accuracy of approximate formulas, as well as illustrate the capabilities of both solutions, the relative concentrations of suspended substance at the exit $\left(\overline{\mathrm{C}}_{\mathrm{e}}\right)$, sediment $(\overline{\mathrm{S}})$ are calculated; head loss $(\Delta \overline{\mathrm{h}})$ and, finally, technological times $\left(\bar{t}_{\mathrm{p}}, \overline{\mathrm{t}}_{\mathrm{h}}\right)[12,14]$. At the same time, own empirical information about the values $\bar{\alpha}, \bar{\beta}, \gamma(\overline{\mathrm{S}}), \overline{\mathrm{k}}(\overline{\mathrm{S}})$ and dependencies (32)-(34), (39), (40), as well as the formula that follows from (38), which allows to calculate the time $\bar{t}_{p}$ directly, is used [14]

$$
\overline{\mathrm{t}}_{\mathrm{p}}=\frac{2}{\bar{\beta}}\left[\frac{\bar{\alpha}}{\ln 2-\ln \left(\overline{\mathrm{C}}_{*}+\mathrm{e}^{-\bar{\alpha}}\right)}-1\right] .
$$

In the experiments, a large amount of suspended substance is found in the initial aqueous suspension, which, for example, is characteristic of industrial wastewater, with $\mathrm{C}_{0}$ varying within fairly wide limits (mass concentration from 100 to $200 \mathrm{mg} / \mathrm{l}$ ). Since $\mathrm{C}_{0}$ is used in modeling as a scale for the desired concentrations, it is necessary to introduce a new scale fixing for this a smaller value from the specified range, that is, $\mathrm{C}_{00}=100 / \rho_{\mathrm{c}}$. Then the subject of the calculations is the current 


$$
\overline{\overline{\mathrm{C}}}=\frac{\mathrm{C}}{\mathrm{C}_{00}}, \overline{\overline{\mathrm{S}}}=\frac{\mathrm{S}}{\mathrm{n}_{0} \mathrm{C}_{00}},
$$

which also depended on $\overline{\mathrm{C}}_{0}=\mathrm{C}_{0} / \mathrm{C}_{00}$, and for the latter three characteristic values were chosen.

To assess the effect of the initial content of impurities in the suspension on the process, formula (41) and equations (40), designed to determine the relative technological times $\bar{t}_{p}, \bar{t}_{h}$, are reduced to the following form. In this connection, in connection with the variation of $\mathrm{C}_{0}$, a parameter $\overline{\mathrm{C}}_{*}=\mathrm{C}_{*} / \mathrm{C}_{00}=\overline{\mathrm{C}}_{0} \overline{\mathrm{C}}_{*}$ is introduced that no longer depends on $\mathrm{C}_{0}$.

$$
\overline{\mathrm{t}}_{\mathrm{p}}=\frac{2}{\bar{\beta}}\left[\frac{\bar{\alpha}}{\ln \left(2 \overline{\mathrm{C}}_{0}\right)-\ln \left(\overline{\overline{\mathrm{C}}}_{*}+\overline{\mathrm{C}}_{0} \mathrm{e}^{-\bar{\alpha}}\right)}-1\right] .
$$

Time $\bar{t}_{\mathrm{h}}$ should now be calculated by fitting from the equation

$$
\Delta \overline{\mathrm{h}}_{*}=\int_{0}^{1} \frac{\left[1+67 \mathrm{C}_{00} \overline{\mathrm{C}}_{0} \overline{\mathrm{S}}\left(\overline{\mathrm{z}}, \overline{\mathrm{t}}_{\mathrm{h}}\right)\right]^{3}}{\left[1+10 \mathrm{C}_{00} \overline{\mathrm{C}}_{0} \overline{\mathrm{S}}\left(\overline{\mathrm{z}}, \overline{\mathrm{t}}_{\mathrm{h}}\right)\right]^{3}} \mathrm{~d} \overline{\mathrm{z}},
$$

where expressions (33), (39) were taken alternately for $\bar{S}(\bar{z}, \bar{t})$.

Relying on the above presented rigorous and approximate solution with the help of personal research data, reviews of relative technological times $\bar{t}_{p}, \bar{t}_{h}$ are specified, hypothetical changes of $\overline{\mathrm{C}}_{0} 2$ times and $\overline{\mathrm{V}} 4$ times. At the same time, the criteria parameters $\overline{\overline{\mathrm{C}}}_{*}$ and $\Delta \overline{\mathrm{h}}_{*}$ are varied. Parameters of graphs of dependences of times $\bar{t}_{\mathrm{p}}, \bar{t}_{\mathrm{h}}$, on $\overline{\mathrm{C}}_{0}$, calculated by accurate (32), (34) and approximate (42), (43) formulas are shown in Fig. 13, 14.

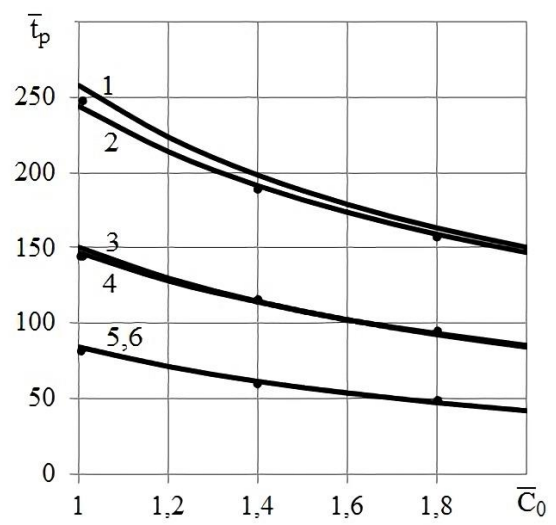

Fig. 13. Dependency $\overline{\mathrm{t}}_{\mathrm{p}}\left(\overline{\mathrm{C}}_{0}\right)$ : 1, 3, 6- approximate calculation; $2,4,5$ - accurate calculation; $1,2-\overline{\overline{\mathrm{C}}}_{*}=0.2 ; 3,4-\overline{\overline{\mathrm{C}}}_{*}=0.1 ; 5,6-\overline{\overline{\mathrm{C}}}_{*}=0.05$

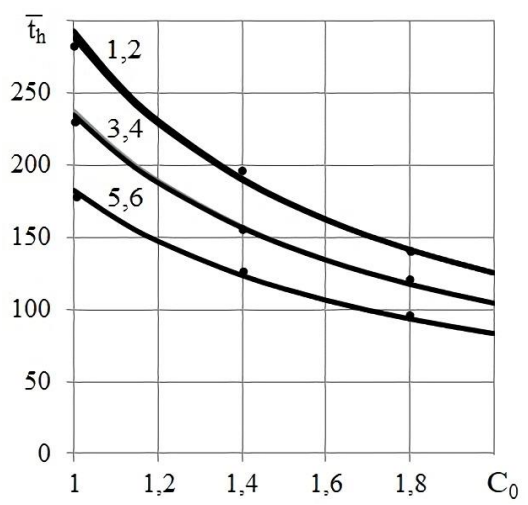

Fig. 14. Dependency $\bar{t}_{h}\left(\bar{C}_{0}\right): 1,3,5$ - accurate calculation; 2, 4, 6 - approximate calculation;

$$
1,2-\Delta \overline{\mathrm{h}}_{*}=6 ; 3,4-\Delta \overline{\mathrm{h}}_{*}=5 ; 5,6-\Delta \overline{\mathrm{h}}_{*}=4
$$


The difference between the corresponding pairs of curves (reference and approximate) turned out to be so small that they merge in the figures, with the exception of the initial sections of curves 1 and 2 . The greatest errors in the calculations $\bar{t}_{\mathrm{p}}, \overline{\mathrm{t}}_{\mathrm{h}}$ occur at the limiting value $\overline{\mathrm{C}}_{0}=1$ and in the case $\overline{\mathrm{C}}_{*}=0,2$ reach $5.5 \%$, and in the case $\Delta \overline{\mathrm{h}}_{*}=6-$ only $1.3 \%$. With an increase in the initial content of impurities, the errors are noted, and with it both technological times are significantly reduced. So, with an increase of $\bar{C}_{0} 2$ times in the same way $\bar{t}_{p}$ decreases. Time $\bar{t}_{p}$ is more sensitive to change $\overline{\mathrm{C}}_{0}$. The term of the filter cycle under the conditions under consideration with a small $\overline{\overline{\mathrm{C}}}_{*}$ limit is limited by the protective property of the filter bed. However, at $\Delta \overline{\mathrm{h}}_{*}=4$ and especially at large values $\overline{\mathrm{C}}_{0}$, the effective filter operation time is limited due to an excessive increase in the hydraulic resistance of the filter bed.

Due to the emphasis $\bar{V}$ in, for example, dependencies with respect to $\bar{t}_{p}$ (32), (41), let's derive a strict equation and an approximate formula

$$
\begin{aligned}
& \mathrm{e}^{-\overline{\bar{\alpha}} \overline{\bar{t}}_{p}} \mathrm{I}_{0}\left(2 \sqrt{\frac{\overline{\bar{\alpha}} \overline{\bar{\beta}} \overline{\overline{\mathrm{t}}}}{\overline{\mathrm{V}}}}\right)+\overline{\bar{\beta}} \int_{0}^{\overline{\overline{\mathrm{t}}_{\mathrm{p}}}} \mathrm{e}^{-\overline{\bar{\beta}} \zeta} \mathrm{I}_{0}\left(2 \sqrt{\frac{\overline{\bar{\alpha}} \overline{\bar{\beta}} \zeta}{\overline{\mathrm{V}}}}\right) \mathrm{d} \zeta=\mathrm{e}^{\overline{\overline{\bar{\sigma}}}} \overline{\mathrm{C}}_{*}, \\
& \overline{\overline{\mathrm{t}}}_{\mathrm{p}}=\frac{2}{\overline{\bar{\beta}}}\left[\frac{\overline{\bar{\alpha}}}{\overline{\mathrm{V}}\left(\ln 2-\ln \overline{\mathrm{C}}_{*}+\mathrm{e}^{-\overline{\bar{\alpha}} / \overline{\mathrm{v}}}\right)}-1\right] \text {, }
\end{aligned}
$$

where

$$
\begin{gathered}
\overline{\overline{\mathrm{t}}}_{\mathrm{p}, \mathrm{h}}=\frac{\mathrm{V}_{0} \mathrm{t}}{\mathrm{n}_{0} \mathrm{~L}}, \\
\overline{\bar{\alpha}}=\frac{\alpha \mathrm{L}}{\mathrm{V}_{0}}, \\
\overline{\bar{\beta}}=\frac{\mathrm{n}_{0} \mathrm{~L} \beta}{\mathrm{V}_{0}} .
\end{gathered}
$$

The results of the calculations $\overline{\bar{t}}_{\mathrm{p}}, \overline{\overline{\mathrm{t}}}_{\mathrm{h}}$, with the same values $\overline{\mathrm{C}}_{*}, \Delta \overline{\mathrm{h}}_{*}$ are shown in Fig. 15, 16 in the form of six accurate and approximate curves, of which curves 3 and 4, 5 and 6 merge, and between curves 1 and 2 in Fig. 15 there are minimal differences (up to $5 \%$ at $\bar{V}=1$ ).

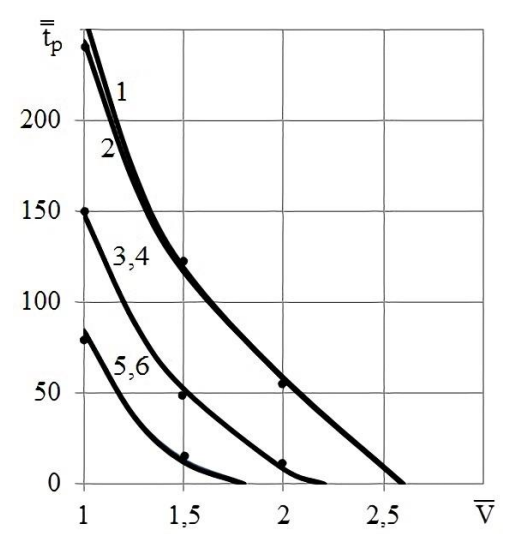

Fig. 15. Dependency $\overline{\overline{\mathrm{t}}}_{\mathrm{p}}(\overline{\mathrm{V}}): 1,3,5$ - accurate calculation; 2, 4, 6- approximate calculation;

$$
1,2-\overline{\mathrm{C}}_{*}=0,2 ; 3,4-\overline{\mathrm{C}}_{*}=0,1 ; 5,6-\overline{\mathrm{C}}_{*}=0,05
$$

Shown in Fig. 15, 16 graphical dependences confirm a significant influence of $\bar{V}$ on the quality of the filtrate especially with strict requirements to it. So when $\overline{\mathrm{C}}_{*}=0,05$ it turns out that the filter is generally not able to provide the necessary clarification level if $\bar{V}>1,75$. 


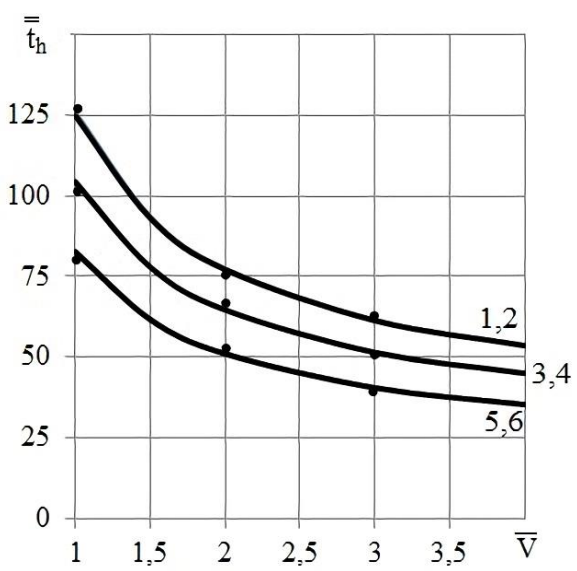

Fig. 16. Dependency $\overline{\bar{t}}_{\mathrm{h}}(\overline{\mathrm{V}}): 1,3,5$ - accurate calculation; 2, 4,6 - approximate calculation; 1 , $2-\Delta \overline{\mathrm{h}}_{*}=6 ; 3,4-\Delta \overline{\mathrm{h}}_{*}=5 ; 5,6-\Delta \overline{\mathrm{h}}_{*}=4$

\section{Discussion of the research results of rapid sand filters}

The analysis of the operating conditions of rapid sand filters in this work allows to recommend a mathematical model for describing the main technological characteristics of these structures: it consists of three blocks: clarification, including mass transfer equations and linear kinetics of mass transfer; filtration - the equation of water movement in a porous filter bed; hydraulic, which includes equations of head loss in communications. Initial and boundary conditions are defined.

On the basis of the obtained research data using special methods for their processing, rates and parameters have been determined that significantly affect the efficiency of filtration structures, in particular, the adhesion coefficient $\alpha$ and the detachment coefficient $\beta$ of suspended particles from particles of the granular bed. It is established that the data are constant at a constant filtration rate and depend on the physicochemical properties of the sediment, the characteristics of the filter material to be removed and should be determined on the basis of additional experimental studies.

It is confirmed that the main parameters that affect the performance of these structures are the quality and properties of the filter material, the height of the filter bed and the time of the filter cycle.

According to the data of experimental studies, the hydraulic resistance of the filter bed is determined when passing a liquid with different concentrations of contaminants. The regularities of changes in the filtration rate of a granular bed with time depending on the filtration rate, the depth of bed and the value of the specific volume of sediment for various conditions and modes of operation of the filter construction are revealed.

The intensity of the removal of contaminants and the degree of their accumulation over time along the height of the filter bed are investigated. It is noted that the maximum rate of these processes takes place in the upper layers of the filter.

\section{Conclusions}

Based on the results of the presented work, the following main conclusions can be made:

1. The analysis of literary sources in which the laws of the process of water clarification on rapid sand filters, head losses in the granular bed, their mathematical modeling, the calculation of the filter cycle and the thickness of the filter bed.

2. Based on the physical model, a general mathematical model of suspension clarification by filtration is substantiated and constructed, which makes it possible to evaluate the influence of various factors and output characteristics on the treatment process.

3. Experimental studies of the main parameters affecting the operation of the rapid sand filter with a variable filtration rate of time are carried out, and the patterns of changes in the treatment effect, head loss, porosity of granular material and filtration rate are determined. 
4. It is established that an increase in the concentration of a sediment $\mathrm{S}$ retained in the filter bed leads to a decrease in its porosity $n$. It is determined that an increase in the relative specific volume of sediment greater than $\Delta \mathrm{n} / \mathrm{n}_{0}=0,65$ practically does not cause further clarification of the suspension.

5. It is shown that the ratio of the volume concentration of sediment to the volume concentration of solid particles in this sediment $\gamma$ is an important characteristic of the retained sediment. An experimental dependence of this indicator on the value of the relative specific volume of sediment is obtained.

6. The values of the adhesion rate $(\bar{\alpha}=4.9)$ and detachment rate $(\bar{\beta}=0.009)$ of contaminant particles from particles of the granular bed are determined.

7. The method of calculating the time of effective operation of the filter (filter cycle), during which the technologically specified cleaning effect is provided, is substantiated and proposed.

\section{Acknowledgement}

The authors are grateful to the Ministry of Education and Science of Ukraine for the financial support of the KNUCA 5 DB-2018 research project, under which this research has been performed.

\section{References}

[1] DBN V.2.5-74:2013. Vodopostachannia. Zovnishni merezhi ta sporudy (2013). Minrehion Ukrainy.

[2] Orlov, V. O. (2005). Vodoochysni filtry iz zernystoiu zasypkoiu. Rivne: NUVHP, 163.

[3] Hudson, H. E. (1959). Declining rate filtration. Journal American Water Works Association, $51(11), 42-50$.

[4] Zhurba, M. (2011). Vodoochistnye fil'try s plavayushchey zagruzkoy. Moscow: RIO VoGTU.

[5] Minc, D. M. (1964). Teoreticheskie osnovy tekhnologi ochistki vody. Moscow: Stroyizdat, 156.

[6] Shevchuk, E. A., Mamchenko, A. V., Goncharuk, V. V. (2005). Tekhnologiya pryamotochnogo fil'trovaniya prirodnyh i stochnyh vod cherez zernistye zagruzki. Himiya i tekhnologiya vody, 27 (4), $369-383$.

[7] Ives, K. J. (1970). Rapid filtration. Water Research, 4 (3), 201-223. doi: https://doi. org/10.1016/0043-1354(70)90068-0

[8] Jegatheesan, V., Vigneswaran, S. (2005). Deep Bed Filtration: Mathematical Models and Observations. Critical Reviews in Environmental Science and Technology, 35 (6), 515-569. doi: https://doi. org/10.1080/10643380500326432

[9] Saatçi, A. M. (1990). Application of Declining Rate Filtration Theory - Continuous Operation. Journal of Environmental Engineering, 116 (1), 87-105. doi: https://doi.org/10.1061/(asce)07339372(1990)116:1(87)

[10] O'Melia, C. R., Ali, W. (1979). The role of retained particles in deep bed filtration. Ninth International Conference on Water Pollution Research, 167-182. doi: https://doi.org/10.1016/b978-0-08022939-3.50019-2

[11] Noskov, M. D., Zayceva, M. S., Istomin, A. D., Lukashevich, O. D. (2008). Mathematical modelling of butterfly filter work. Vestnik TGASU, 2, 126-137.

[12] Grabovskyi, P. A. (2016). Water filtration through a grainy layer with decreasing rate. Reports of the National Academy of Sciences of Ukraine, 8, 40-45. doi: https://doi.org/10.15407/dopovidi2016.08.040

[13] Gurinchik, N. A. (2010). Opredelenie prodolzhitel'nosti raboty fil'trov dlya raznyh rezhimov fil'trovaniya. Visnyk ODABA, 42, 56-62.

[14] Polyakov, V. L. (2012). Suspension filtration at declining rate and linear mass-exchange kinetics. Himiya i tekhnologiya vody, 34 (2), 107-130. 
[15] Polyakov, V. L., Kravchuk, O. A. (2015). Matematicheskoe modelirovanie osvetleniya suspenzii fil'trovaniem s sushchestvenno peremennoy skorost'yu. Visnyk Odeskoi derzhavnoi akademiyi budivnytstva ta arkhitektury, 59, 331-337.

[16] Zhurba, M. G. (1980). Ochistka vody na zernistyh fil'trah. Lviv: Vyshcha shkola, 199.

[17] Girikov, O. G., Nikolaev, E. Yu. (1999). Intensifikaciya raboty skoryh vodoprovodnyh fil'trov. Izvestiya vuzov. Stroitel'stvo, 7, 128-131.

[18] Saiers, J. E., Hornberger, G. M., Liang, L. (1994). First- and second-order kinetics approaches for modeling the transport of colloidal particles in porous media. Water Resources Research, 30 (9), 24992506. doi: https://doi.org/10.1029/94wr01046

[19] Polyakov, V. L. (2009). Filtration of a suspension with variable content of suspended particles through a uniform filter medium at a nonlinear mass-exchange kinetics. Reports of the National Academy of Sciences of Ukraine, 12, 61-68.

[20] Ojha, C. S. P., Graham, N. J. D. (1993). Theoretical estimates of bulk specific deposit in deep bed filters. Water Research, 27 (3), 377-387. doi: https://doi.org/10.1016/0043-1354(93)90037-i

[21] Polyakov, V. L. (2009). Teoreticheskiy analiz dlitel'nosti fil'trocikla. Himiya i tekhnologiya vody, 31 (6), 605-618.

[22] Polyakov, V. L. (2010). On the prediction of the head loss dynamics within a filter medium. Reports of the National Academy of Sciences of Ukraine, 3, 70-76.

[23] Polyakov, V. L. (2011). Calculation of suspension filtration through two-layer filter medium at linear mass-exchange kinetics. Himiya i tekhnologiya vody, 33 (4), 367-380. 